\title{
El papel de la academia. Sobre Filosofía y Letras (1998) de Pablo De Santis*
}

\author{
The Role of the Academy. On Filosofía y Letras (1998) by Pablo De Santis
}

Hernán Maltz ${ }^{\mathrm{a}}$

DOI: https://doi.org/10.11144/Javeriana.cl24.pafl

Universidad de Buenos Aires, Argentina

hermaltz@gmail.com

Recibido: 02 Agosto 2018

Aceptado: 20 Febrero 2019

Publicado: 28 Diciembre 2020

\section{Resumen:}

En el marco de un corpus de escritores de relatos policiales académicos argentinos (que incluye a autores como Ricardo Piglia y Guillermo Martínez), en este escrito planteamos un acercamiento a dicho subgénero a partir de la novela Filosofía y Letras (1998) de Pablo De Santis. De este modo, mostramos y analizamos tres aspectos sustantivos de esta obra: la representación de los académicos como sujetos locos y miserables, la construcción de una trama policial que carece de una figura detectivesca fuerte y la representación del edificio de la Facultad de Filosofía y Letras (edificio que termina por ser el gran protagonista de la novela).

Palabras clave: género policial, Pablo De Santis, academia, Facultad de filosofía y letras.

\section{Abstract:}

In the context of a corpus of Argentinian academic crime fiction writers (which includes authors such as Ricardo Piglia and Guillermo Martínez), in this paper I propose an approach to this sub-genre based on the novel Filosofía y Letras (1998) by Pablo De Santis. I thus show and analyze three substantive issues of this novel: the representation of academics as crazy and miserable subjects, the construction of a crime fiction plot lacking the presence of a strong detective figure and the representation of the building of the Faculty of Philosophy and Letters (building that finally becomes the protagonist of the novel).

Keywords: Crime fiction, Pablo De Santis, academy, Faculty of philosophy and letters.

\section{Introducción}

En su ambiciosa antología de cuentos policiales argentinos de 1997, Lafforgue afirma que "[n]ingún otro género, como el policial, ha estructurado tan raigalmente el sistema de la ficción argentina a lo largo de este siglo [XX]" ("Prólogo" 11). En efecto, apellidos como los de Borges, Walsh y Piglia le otorgan una legitimidad difícil de hallar en los desarrollos del género policial en otros países. Tanto así que incluso se ha planteado la existencia de un "imperativo del policial" (Contreras 142) que tiende a funcionar como un parámetro regulativo de consagración en las letras argentinas.

Una útil clasificación de la literatura policial considera la existencia de dos vertientes: una clásica, de enigma, inglesa y otra negra, "dura", norteamericana — por mencionar al menos tres denominaciones que recibe cada vertiente- Por ejemplo, Gamerro (79) y Siegrist (1994) son dos críticos que sostienen esta clasificación para la Argentina y América Latina, respectivamente, aunque, por supuesto, al ser una clasificación, su empleo resulta debatible. De cualquier modo, insistimos, se trata de una grilla general de interpretación del género que aún hoy resulta válida (especialmente frente a algunas perspectivas que ya dan por finalizada la vertiente clásica y piensan en una gran etiqueta de "género negro" que, a fin de cuentas, borra toda una corriente de esta literatura).

Sin embargo, cuando nos adentramos en la densidad del género policial argentino, podemos distinguir distintas subvertientes y conjuntos específicos de textos. En esta dirección, un pequeño pero significativo corpus de ficciones nos permite concebir un relato policial académico argentino ${ }^{1}$ desde el cuento "La loca

Notas de autor

a Autor de correspondencia. Correo electrónico: hermaltz@gmail.com 
y el relato del crimen" (1975), de Ricardo Piglia, pasando por las novelas El agua electrizada (1992), de Carlos Feiling; Filosofía y Letras (1998) y La traducción (1998), de Pablo De Santis; La Cátedra (2000), de Nicolás Casullo; Crimenes imperceptibles (2003), de Guillermo Martínez; El icono de Dangling, de Silvia Maldonado; hasta El camino de Ida (2013), del propio Piglia. ${ }^{2}$ Desde luego, cada uno de estos textos posee una forma particular de representar el mundo académico, pero, al menos, podemos agruparlos bajo el común denominador de que seleccionan personajes universitarios que encabezan -o sufren - investigaciones sobre crímenes y/o que están en los ámbitos académicos en los que tales crímenes se producen. ${ }^{3} \mathrm{Y}$, por supuesto, la selección de personajes y ámbitos universitarios acarrea, por lo general, la elaboración de discursos literarios que también incluyen problemas, temas, motivos, objetos y relaciones inherentes al mundo académico.

En este marco, la figura de Pablo De Santis (Buenos Aires, 1963) se convierte en una posible referencia para una indagación sobre dicha vertiente específica del género policial argentino, en particular, a través de sus novelas Filosofia y Letras (1998) y La traducción (1998), aunque sus obras posteriores, El enigma de París (2007) y Crimenes y jardines (2013), también podrían ser analizadas en el mismo sentido. Si bien distintos críticos mencionan la dirección policial de la narrativa de De Santis — Saítta ("Un thriller" 74), Gamerro (79-91), Néspolo (153-162), Konstantinova ("Detectives" 196-206; "Borgesian Texts" 161-176), Wieser (66-82) y Jacovkis (115-129) —, no se suele ahondar en el significativo vínculo entre lo policial y lo académico que construyen Filosofía y Letras y La traducción (con la excepción de los trabajos de Saítta y Konstantinova).

Ciertamente, Filosofía y Letras puede ser clasificada como una novela policial, pero esta cualidad no debería ser disociada de su condición académica. Su historia se desarrolla en un espacio cerrado, una sede de la Facultad de Filosofía y Letras de la Universidad de Buenos Aires, en la calle 25 de Mayo, en donde un grupo reducido de profesores - Conde, Granados y Novario, pero también Trejo y Miró- se disputan la inaccesible obra del incierto Homero Brocca, del que apenas llegamos a leer una versión del cuento "Sustituciones". A partir de esta historia, en nuestro trabajo nos interesa mostrar y analizar tres cuestiones: la representación de los académicos como sujetos locos y miserables, la construcción de una trama policial que carece de una figura detectivesca fuerte y, por último, la representación del edificio de la Facultad de Filosofía y Letras como el gran protagonista de la novela. Así, en la elaboración de una ficción con estos tres elementos, identificamos en Filosofía y Letras un significativo exponente de la mencionada vertiente de los relatos policiales académicos argentinos.

\section{Los locos y el relato del crimen: académicos, policial y locura en "La loca y el relato del crimen", de Piglia, y Filosofía y Letras, de De Santis}

En mayor o menor medida, los trabajos que abordan Filosofía y Letras ponderan en sus análisis la presencia del "factor Borges". Se trata, desde luego, de una correlación necesaria e inevitable, aunque esto no debe obnubilar la posibilidad de otras interpretaciones. En este sentido, en nuestra lectura de la novela de De Santis consideramos pertinente establecer un vínculo con el cuento "La loca y el relato del crimen" (1975), de Ricardo Piglia. ${ }^{5}$ Se trata de una conexión que podemos trazar en al menos dos aspectos.

Por un lado, "La loca y el relato del crimen" es un texto que avala el ingreso de la academia en el relato policial (Sasturain). ${ }^{6}$ Esta operación se da a través de la resolución del enigma, que viene dada por el saber lingüistico de Emilio Renzi (Rivera 101). ${ }^{7}$ Sin embargo, Filosofía y Letras trastoca ese vínculo establecido: si bien hace ingresar literalmente al relato policial en la academia, en el viejo edificio de la Facultad de Filosofía y Letras, ${ }^{8}$ lo hace con una modalidad inversa, pues en este caso la academia no proporciona claves resolutivas, e, incluso, hay seis muertes en su entorno (tres profesores, dos no-docentes y un estudiante, y todas estas muertes suceden en el devenir de la historia narrada por Miró, salvo la del estudiante Honorio, que es referida con anterioridad a la presencia de Miró, a través de la voz de Novario). Si en el relato de Piglia la academia viene 
de afuera para brindar una solución, en la novela de De Santis lo policial penetra en la facultad para cobrarse varias víctimas. Así, la academia no facilita la resolución del enigma en Filosofía y Letras, aunque sí participa en la recreación de elementos del género policial: un ambiente cerrado, una cantidad reducida de personajes - la mayoría sospechosos - y una serie de muertes en torno a otro enigma: la vida desconocida del escritor Homero Brocca. ${ }^{9}$

Por otro lado, hallamos una similitud en un aspecto puntual que contienen ambos textos: la imagen de un académico que se interesa en las palabras —orales o escritas - de un loco. En el caso de "La loca y el relato del crimen", Renzi decodifica el mensaje de Angélica Inés Echevarne, en los intersticios de su discurso patológico-iterativo, y así resuelve el caso. ${ }^{10}$ En Filosofía y Letras tenemos a Rusnik, un paciente de una residencia psiquiátrica - la Casa de reposo Spinoza - aquejado por un síndrome que lo compele a escribir todo el tiempo, incluso en los sueños — el "mal de Van Holst", según se lo titula en la novela_, y al profesor Emiliano Conde, quien condiciona y toma esos textos, los depura y saca de ellos el material para "completar" la narrativa perdida del incierto Homero Brocca. ${ }^{11}$ De esta analogía podemos desprender, empero, una nueva diferencia: en el texto de Piglia, la academia contribuye a elaborar una hipótesis original que permite develar al verdadero asesino; al contrario, en la novela de De Santis, el universitario que lee al loco lo explota en beneficio de sus propios fines y para confundir a los otros profesores. Otra diferencia con el relato de Piglia es que, en este último, las palabras de Echevarne contienen en potencia la develación del asesino. En contraposición, en Filosofía y Letras, Brocca es él mismo el asesino, además de que resulta, en buena medida, el responsable de la destrucción del edificio de la facultad.

La búsqueda y la interacción con las palabras de los locos parece configurar, en gran medida, la estructura de toda la novela: no solo Conde lee a Rusnik, sino que todos los académicos persiguen (con locura) la obra de Brocca. Miró finalmente consigue leer un texto completo del escritor y luego se transforma en una suerte de copista de la novela perdida de un loco, aunque su "versión de los hechos" (De Santis, Filosofía 11, 222) aporta una distancia que le permite apropiarse de manera inteligible de ese discurso. ${ }^{12}$ Miró también dedica su tesis doctoral —aunque la posponga de manera sistemática - al estudio de Enzo Tacchi, otro autor incierto, quien "tomaba nota de las palabras de los locos a través de un sistema taquigráfico de su invención" (De Santis, Filosofía 16). Y Miró lee las memorias del doctor Brest, estudioso de los locos que "había elegido sus treinta pacientes más interesantes para describir sus patologías" (De Santis, Filosofía 101). ${ }^{13}$ Los profesores Conde, Granados y Novario se increpan a lo largo de toda la novela y se tildan los unos a los otros de locos y mentirosos, entre otras injurias. La impresión de Miró, cuando conoce a Gaspar Trejo, lleva la misma marca: "Pensé que estaba frente a un loco. Los locos siempre abundaron en la facultad" (De Santis, Filosofía 88). El propio Trejo refiere su primera investigación, acerca de la desaparición de unas máquinas de escribir de la facultad, como un misterio que se resuelve con el descubrimiento de un profesor que desvariaba:

No había robado las máquinas por dinero, sino porque necesitaba dormir rodeado de máquinas de escribir con una hoja en cada una. Aseguraba que los fantasmas que había en su casa en lugar de perturbar su sueño escribían de tanto en tanto algún mensaje y se conformaban con eso, dejándolo en paz. (De Santis, Filosofía 90-91)

Otro ejemplo que marca el nivel de locura del ámbito académico lo encontramos en una breve interacción de Miró con el sereno. Este último toma la palabra:

-Recorro el edificio a la noche, pero estoy al tanto de lo que ocurre durante el día. Sé quién es usted, sé quién es cada uno. Los miro desde arriba, sé adónde van y por qué. Allá arriba hay una carpeta para cada uno donde está escrito su destino. Nadie puede encontrar su expediente. Y yo cuido que así sea.

Se acercó. Vi su boca, la barba de unos pocos días, la nariz grande.

- Soy un instrumento del destino. Escribo en actas todo lo que pasa y lo que pasará. (De Santis, Filosofía 121)

Aquí tenemos una prolepsis de la verdad, pero que, anticipada y revelada a Miró de manera prematura, es entendida como un delirio del sereno (en este punto de la narración aún no sabemos que el sereno es Brocca). 
El propio Miró piensa: "En algún momento de la breve conversación, tuve la lucidez suficiente para darme cuenta que estaba en las manos de un loco. Y empecé a alejarme lentamente” (De Santis, Filosofía 121).

En general, los personajes de la novela no escapan a la locura, pues esta tiende a circular entre todos ellos, menos como un atributo que los constituye que como un problema con el que tienen que lidiar, pero del que eventualmente se pueden desprender. Por ejemplo, si el carácter despojado — de las cosas y del orden social- de Grog lo convierte en un sujeto sabio, él mismo reconoce un pasado aquejado por el "síndrome de Marconi": "Una enfermedad que lo condenaba a imaginar vastos textos literarios sin que llegara a escribir una sola línea” (De Santis, Filosofía 156). Este antiguo problema había convertido temporalmente a Grog en un paciente de la Casa Spinoza: un refugio para intelectuales que deviene en un hospicio de locos. En esa transformación podemos notar, por supuesto, una conexión entre los intelectuales y los locos. De hecho, en otra referencia a la Casa Spinoza, relativa a un tiempo presente del hospicio, una de sus empleadas la describe como "un refugio para las mentes brillantes que no soportan la realidad" (De Santis, Filosofia 96; énfasis propio). Y el viejo bibliotecario del lugar reconoce el - posible- carácter transitorio de la locura: "Yo era paciente [...]. Estuve tantos años internado que al final me tomaron como empleado. Otros hacen el camino inverso" (De Santis, Filosofía 97). En suma, podemos servirnos de una formulación de Foucault para sintetizar esta circulación integral de la locura en Filosofía y Letras, cuyos personajes no se encuentran " $a$ distancia de la locura, sino en la distancia de la locura" ("La locura, la ausencia" 271; énfasis del original).

La mención de Foucault también nos permite retomar otra idea de este autor relativa al vínculo entre literatura y locura, pues ambas constituyen discursos que no están sujetos a las obligaciones y las reglas del lenguaje cotidiano: "La locura y la literatura son marginales respecto del lenguaje cotidiano y se busca el secreto de la producción literaria general en un modelo que es la locura" ("La locura y la sociedad" 365). Dicha idea resulta atinada para pensar la producción literaria en Filosofía y Letras, pues son los locos quienes llevan a cabo las empresas literarias de la historia, entre las que destaca, desde luego, la versión de Filosofía y Letras de Brocca. ${ }^{14}$

En síntesis, la novela de De Santis trabaja con una imagen iterativa: un académico que lee el texto de un loco y lo jerarquiza; una persona que percibe en otra la figura de un loco; una persona que escucha a un loco porque tampoco tiene alternativa; e, incluso, la autoconciencia - la asunción o la confesión- de la propia locura. En esta imagen de locos que señalan, tratan, leen e interpretan a otros locos, hallamos que Filosofía y Letras renueva y multiplica el esquema abierto por "La loca y el relato del crimen". Sin embargo, la comparación trazada reconoce un punto de quiebre entre ambos textos: si en el de Piglia el discurso académico sirve para ordenar el de la locura, en Filosofía y Letras ese sueño de la razón produce locos.

\section{Crítica de los críticos sin crítica: la representación de los académicos como individuos miserables}

En Filosofía y Letras observamos que la jocosa representación y la mofa del mundillo académico se enfoca en mostrar la incapacidad de sus profesores para resolver los enigmas que plantea el género policial, en contraste con el parámetro que marcan otras ficciones, como "La loca y el relato del crimen"; Crímenes imperceptibles (2003), de Guillermo Martínez, o El camino de Ida (2013), del propio Piglia. Esos son textos en los que podemos valorar al sujeto académico como un sagaz investigador, y no como un tramposo, cínico y manipulador al que no le interesa nada más que enaltecer su propia figura, como es el caso de los tres profesores de Filosofía y Letras, "especialistas” en Homero Brocca: Emiliano Conde, Selva Granados y Víctor Novario. Así, si bien la representación de estos universitarios posee un efecto mayormente humorístico, asimismo hace inteligible el ámbito académico como un campo de constantes desigualdades, tensiones, luchas y diversas formas de dominación, tal como lo entiende Bourdieu (Homo academicus 99-169). De este modo, los personajes de De Santis retratan a los académicos como administradores de la miseria, como resentidos 
que pugnan por presidir congresos desiertos y firmar trabajos que no le interesan básicamente a nadie por fuera de su entorno.

El carácter miserable del mundillo académico, entonces, resulta el objeto de un tratamiento humorístico. Los críticos no resuelven enigmas; más bien, crean problemas, distorsiones y mentiras. Ante este panorama, es útil contraponer la composición de los profesores de Filosofía y Letras con una idea de Piglia -basada, posiblemente, en una de Chesterton - que consta de tres partes: a) "La novela policial es la gran forma ficcional de la crítica literaria"; b) el crítico actúa como un investigador, como un "descifrador de enigmas", y c) el escritor se aproxima a la figura de un "delincuente que borra sus huellas y cifra sus crímenes perseguido por el crítico" (Piglia, "La lectura" 15). ${ }^{15}$

Si tomamos por separado los tres elementos citados, vemos que en la novela de De Santis hay una ruptura con todos ellos: en primer lugar, en lo que respecta a la concepción del género policial como la gran forma ficcional de la crítica literaria, podemos insistir en que lo policial, como factor de indagación inherente a la actividad crítica, está ausente (aunque sí hay un registro de lo policial en la novela, pero vinculado a efectos de ambientación y a los rasgos de algunos personajes, así como a la presencia del misterio como motor de la trama). En segundo lugar, ya hemos advertido que la representación del crítico como investigador se encuentra transformada en la novela de De Santis, pues, antes que seguir huellas, los profesores inventan datos falsos y se calumnian e insultan entre ellos. En tercer lugar, podríamos afirmar que en Filosofía y Letras se da la coincidencia del escritor - o, mejor dicho, de uno de los escritores de la novela- con la figura del delincuente, aunque, de nuevo, hay una diferencia significativa: si el escritor-delincuente de Piglia borra sus huellas, en el caso de Homero Brocca se trata de un asesino que, a fin de cuentas, quiere dar a conocer su obra, y para ello permite que Miró conserve la vida y lea toda su novela.

Contrariamente a la línea Piglia-Chesterton, podemos pensar una lectura de Filosofía y Letras como una critica de los críticos sin critica. ${ }^{16}$ A lo largo de toda la novela, nos vemos tentados de tomar nota de las diferentes y variadas mañas de los académicos: Granados irrumpe en el Instituto de Literatura Nacional sin saludar (De Santis, Filosofía 17); Conde desestima el tema de estudio de Miró y es pesimista sobre una posible modificación ("Temas menores no, por favor. Pero bueno, ya es tarde para cambiar de rumbo" [24]); el propio Conde tilda a Granados de "loca” y se refiere a los otros profesores como "buitres" (24); a su vez, Granados se refiere a él como "pedante" y "egoísta” (28). Los ejemplos, lejos de agotarse en las primeras páginas, persisten a lo largo de toda la historia: chicanas, chantajes, comportamientos hipócritas, falsas promesas, discordias sistemáticas, etc. Salvo por la lujuria, cada uno de los pecados capitales encuentra su lugar en la trama. Incluso la gula: Granados, Novario y Miró toman un "aperitivo" antes de emprender una excursión al cuarto piso — "tres latas de cerveza, salamín y aceitunas” (64) - , y luego de la expedición terminan con los víveres restantes en una "cena improvisada" (72), con la llamativa curiosidad de que este episodio se da después del descubrimiento del cadáver del intendente Vieyra.

En suma, ante los elementos expuestos, y según esta visión de la crítica de los críticos sin crítica, podemos sugerir una línea de lectura de Filosofía y Letras como un inventario burlón de los vicios académicos, del que aquí apenas brindamos un panorama. ${ }^{17}$

\section{Indiciología del policial: en busca de una subjetividad detectivesca}

Como ya lo señalamos, en Filosofía y Letras hay una recreación indudable de elementos ligados al género policial: un ambiente cerrado, una cantidad reducida de personajes - la mayoría sospechosos- y una serie de muertes en torno a otro enigma: la vida desconocida del escritor Homero Brocca. ${ }^{18}$ Pero, además, observamos que en esta adscripción al policial predomina un uso del género como ejercicio de humor. ${ }^{19} \mathrm{~A}$ continuación, repasamos el tratamiento que recibe un aspecto particular de esta línea de lectura genérica. 
Borges ("El cuento" 69-88) y Piglia ("Lectores" 77-102), entre otros, indican al detective como la clave formal del relato policial. Sin embargo, en la novela de De Santis notamos que, según la fórmula coloquial, "Entre todos [los personajes] no hacen uno". Ya hemos mencionado que los tres profesores, Conde, Granados y Novario, distan de ser críticos en el sentido pigliano-chestertoniano, por lo que ellos, más bien, se colocan en las antípodas del investigador. De cualquier modo, sí podemos rastrear una subjetividad de detective fallida, aunque ella se presente de manera fragmentada — con un indudable cariz humorístico-, y repartida entre otros tres personajes.

En primer lugar, debemos reconocer que el torpe accionar de Esteban Miró garantiza, a fin de cuentas, una aproximación al esclarecimiento de la serie de muertes ocurridas. Desde luego, se trata de un observador parcial del que tenemos pleno derecho de desconfiar, pero no podemos dejar de tener presente que, si hay una versión de los hechos que nos llega, es gracias a la redacción de su informe académico. ${ }^{20}$ Además de su faz de escritor, Miró lee novelas policiales, o al menos las acumula en su mesa de luz. Incluso, despliega cierto conocimiento interpretativo cuando descubre muerto al intendente Vieyra y advierte, en la soga que rodea el cuello del cadáver, un mensaje destinado solo a los conocedores de la obra de Brocca (pues se trata de un motivo que aparece en el cuento "Sustituciones"). Asimismo, contemplamos la conformación de una suerte de dupla junto a Trejo, con una clara resonancia de las parejas de detective y ayudante del relato policial clásico. Pero este recurso funciona con una marcada distancia frente al género y un indiscutible tono de burla jocosa:

Me asomé con respeto al pozo negro. Aunque había poco más de dos metros hasta el techo del ascensor, me parecía un abismo. Trejo me tendió la mano para ayudarme a bajar.

-Fácil su trabajo. Juega al detective, pero manda al doctor Watson al foso.

-Créame, Miró, más sufro yo que usted imaginándolo ahí abajo entre la mugre y las cucarachas. Pero tengo claustrofobia, además de un temor enfermizo a los insectos. (De Santis, Filosofía 137-138)

En segundo lugar, Grog podría hacer las veces de observador externo, que es el papel del detective clásico: esa suerte de conciencia que flota por sobre la realidad del orden social (Kracauer 73-89). Grog es el líder espiritual de un grupo de amigos cada vez más reducido (en la medida en que ellos se casan, consiguen trabajos, etc.), que se junta los miércoles por la noche en la pizzería El Caimán (y, después de su derrumbe, en un bar que Miró llama La Angustia). Se trata de un personaje que rehúsa cualquier modalidad de inserción legítima en el sistema social y siempre narra parábolas e historias con moralejas ininteligibles (o que, en todo caso, solo son entendibles desde una mirada externa a la sociedad). Miró lo presenta incluso como un lector-traductor especialista del género policial: "Años atrás su medio de vida había sido la traducción de novelas policiales. Uno de sus temas favoritos era rescatar la figura de Agatha Christie contra la corriente que ubicaba a sus libros en un plano inferior a la sobrevalorada novela negra” (De Santis, Filosofía 93). ${ }^{21}$ Sin embargo, este retrato de Grog como un outsider del orden social se pulveriza cuando Miró descubre la figura del padre de familia y trabajador asalariado que se esconde tras la imagen bohemia que da de sí:

Seguí a Grog a prudente distancia durante un par de cuadras. Lo oí silbar una canción de moda. Se detuvo frente a una casa de un piso, con el frente recién pintado. Buscó en sus bolsillos las llaves, y al no encontrarlas tocó el timbre. Salió a recibirlo una mujer joven, bastante bonita y notablemente embarazada. Pronto se asomó un niño de unos cinco años que se abrazó a las rodillas de Grog. No puedo expresar la desazón que sentí frente a aquella escena de felicidad doméstica. (De Santis, Filosofia 150)

Este fragmento resulta altamente ilustrativo para marcar una oposición con el detective clásico, indiferente a los valores burgueses de la familia y el hogar. Desde luego, tenemos aquí el punto de inflexión por el cual Grog - "Grogenstein" (155), puesto que con este evento Miró le restituye su "nombre social" - se separa definitivamente de una subjetividad asimilable al detective tradicional.

En tercer lugar, el profesor Gaspar Trejo, titular de una "cátedra portátil", ${ }^{22}$ es asociado explícitamente a la figura del detective. Se autoproclama como "una especie de investigador privado" (89) y Miró se refiere a él en distintas ocasiones como un "detective universitario" $(137,158,162)$. En contraste con el narrador de $E l$ 
camino de Ida, de Piglia, que se desempeña como un eficaz detective académico, en la novela de De Santis este sintagma posee una clara valoración oximorónica: es justamente "lo universitario", "lo académico", aquello que inhibe a Trejo de llegar a un esclarecimiento de los hechos. En este personaje hallamos, sin dudas, una burla festiva al método indiciario y positivista con que el detective clásico arriba a la verdad. Trejo le comenta a Miró su intención de institucionalizar el saber de la denominada "indiciología” (170): "Había abandonado la lógica pura para construir mi propia materia, la Ciencia de los Indicios. Quería convertir en filosofía la tendencia a buscar la verdad en los detalles irrelevantes" (De Santis, Filosofía 89). Podríamos sostener que la indiciología, como parodia del método indiciario de los relatos policiales clásicos, pone en duda menos la posibilidad del conocimiento que su pertinencia: la opción de llegar a una verdad relevante parecería difícil si se parte de "detalles irrelevantes". A diferencia del policial clásico, en que el detective reúne indicios para generar una interpretación que permita recrear los hechos, Trejo los acumula en un museo, y esta musealización tiende a clausurarlos como potenciales claves resolutivas. Además, resulta inevitable no concebir la "Ciencia de los Indicios" en vínculo con el paradigma indiciario conceptualizado por Ginzburg, que consiste en ponderar los elementos que habitualmente se consideran poco importantes, en apariencia triviales, pero que, finalmente, dan la clave interpretativa de un problema (171-221). Al contrario, en Filosofía y Letras observamos una suerte de mofa de dicha matriz explicativa, pues los detalles que se presentan como irrelevantes son, a fin de cuentas, igualmente irrelevantes.

El mismo Trejo reconoce que se dedica a investigar casos de delitos académicos menores, de modo que su participación en la investigación de la muerte del intendente Vieyra lo hace sentir "como un auténtico detective" (De Santis, Filosofía 91), y en esta afirmación hallamos una asunción bastante explícita de su carácter más teatral que real, en tanto detective. Sin embargo, hay unas palabras de Trejo que terminan por ser, a nuestro criterio, iluminadoras de toda la novela: "Con la razón sola no se llega a ninguna parte. Solo admitiendo que la realidad es en gran parte imaginaria se puede alcanzar la verdad" (De Santis, Filosofía 90). Más allá de las posibles resonancias borgeanas, consideramos que, gracias a esta clave hermenéutica que facilita, se le puede restituir a Trejo un genuino carácter detectivesco. Pero esta revelación salida de sus palabras no opera en la resolución del enigma concreto de la novela - la serie de muertes-, sino en un sentido que lo excede. Konstantinova, en su comparación de Filosofía y Letras con "El jardín de senderos que se bifurcan" de Borges, ve en ambos textos una dimensión del denominado relato policial metafísico ("Borgesian Texts" 164-166). La estudiosa se sirve de la conceptualización efectuada por Merivale y Sweeney, quienes definen este subgénero (the metaphysical detective story) como

un texto que parodia o subvierte las convenciones del policial clásico [...] con la intención, o al menos el efecto, de plantear preguntas acerca de los misterios sobre el ser y el conocimiento que trascienden las meras maquinaciones del misterio de la trama. Los policiales metafísicos usualmente enfatizan esta trascendencia también convirtiéndose en auto-reflexivos (esto es, representando alegóricamente el propio proceso de composición textual). (2; traducción propia) ${ }^{23}$

Así, si en Trejo vemos una dificultad para emplear el tradicional método indiciario de detección, al mismo tiempo notamos una capacidad de abstracción que discurre sobre las posibilidades mismas del conocimiento. Este pensamiento puede ser complementado con otro, en boca de Miró, en relación con una prototeoría sobre la espacialidad del conocimiento. Cuando, junto al propio Trejo, escucha un casete de la ya difunta Granados, Miró reflexiona: "La muerte, esa distancia, empezaba a limar sus peores rasgos y le inventaba [a Granados] un halo de simpatía. 'Quién sabe - pensé-, si al final es la distancia, y no la cercanía, lo que convoca mejor a la verdad"'(De Santis, Filosofía 140; énfasis propio). Pues bien, si en cierto tipo de detectives la presencia en el lugar de los hechos es fundamental para recabar evidencias, aquí tenemos un pensamiento que relativiza ese rasgo automatizado en muchos relatos policiales positivistas (y, en esa valoración de la distancia, vale recordar el ejemplo paradigmático de don Isidro Parodi, el detective de Borges y Bioy Casares que resolvía sus casos desde el encierro de una celda penitenciaria). 
En síntesis, Miró, Grog y Trejo se nos presentan como tres personajes que traen a cuenta fragmentos de la figura del detective clásico. A través de ellos, observamos que Filosofía y Letras parodia y, en el mismo movimiento, obliga a pensar y repensar el género, al poner en cuestión la figura del detective, sus características y sus métodos.

[T2]El papel del lugar de los hechos: la representación de la Facultad de Filosofía y Letras

Ante la dispersión que hallamos en la búsqueda de una "subjetividad detectivesca", podemos llegar al verdadero protagonista del libro: el antiguo edificio de la Facultad de Filosofía y Letras —y, más precisamente, su representación en la ficción-.

Como sostiene Konstantinova, en la novela hay una serie de tres narrativas separadas, todas con el mismo título -Filosofía y Letras -, que convergen en una sola: la de Brocca, la de Miró y la del propio De Santis (174). Sin embargo, no debemos dejar de tener presente que, también, hay una apelación sistemática a un referente concreto: el edificio de la Facultad de Filosofía y Letras de la calle 25 de Mayo 217/221. Desde luego, la novela elabora una versión fictiva de este espacio, pero no deja de ser una construcción en el papel que tiene como referente un lugar que existe de hecho en la Ciudad de Buenos Aires. ${ }^{24}$ En este sentido, la presencia del edificio, junto al trasfondo de otros espacios identificables de la ciudad —el barrio de Once, los viejos vagones destartalados de la línea A de subtes, la nueva sede de la Facultad de Filosofía y Letras que es mencionada tácitamente al comienzo, cuando se dice que los nuevos estudiantes no conocen la vieja sede-, habilita la configuración de un orden representacional de lo urbano que parte de elementos reales, aunque luego tienda hacia lo fantástico: por ejemplo, a través de la presencia exhaustiva de papeles y carpetas que pasan a formar parte de la propia arquitectura del edificio de la facultad.

Si Saítta sostiene, a través de la lectura de diversos autores (Arlt, Marechal, Borges, Piglia), que la literatura construye sentidos fuertes de representaciones de la ciudad ("Ciudades" 135-149), pareciera que en Filosofía y Letras esta potencia de la ficción figura enrevesada con su propia negación, a través de la representación de un espacio que ya no existe a los ojos de casi nadie - ni los propios estudiantes, que cursan en otra sede- $-\mathrm{y}$ que contrasta con los otros edificios de la city porteña: "Rodeado de bancos y casas de cambio y bares para ejecutivos, el edificio parecía aún más pobre y desamparado por contraste con la riqueza de sus vecinos" (De Santis, Filosofía 13). En efecto, el principal calificativo que recibe el edificio a lo largo de la novela es su carácter desértico (De Santis, Filosofía 63, 73, 118, 120, 129, 130, 135, 137, 143, 214). Así, la facultad adquiere una suerte de centralidad marginal: la ficción la constituye como el punto ponderado de una ciudad que, en verdad, casi la ha olvidado. En la novela todo conduce a la facultad, pero, a su vez, a nadie externo le importa lo que allí sucede: podemos traer a colación, como ejemplo, el desinterés del periodismo en cubrir el congreso académico sobre Brocca, así como la risible promesa de televisar dicho evento después del cine de trasnoche. ${ }^{25}$ Más bien, entonces, notamos que la facultad tiende a totalizar la ciudad vivida por Miró (la ciudad mediada por Miró es, a fin de cuentas, la única representación de la ciudad que nos llega):

El edificio me perseguía: adonde yo iba, la facultad extendía sus pasillos desiertos y sus aulas oscuras; en cualquier esquina de la ciudad podía encontrar una pila de papeles como mensaje. El laberinto del cuarto piso me había seguido hasta allí. (De Santis, Filosofia 142-143)

Además, si en el presente de la enunciación de la novela el edificio resulta extraño frente al paisaje porteño, en su interior hallamos una conexión con el pasado de la ciudad, y en ese vínculo con una configuración urbana que ya no existe se confirma la anacronía del viejo edificio de la Facultad de Filosofía y Letras:

El edificio de la facultad es uno de los puntos clave de la red de túneles que recorre la ciudad antigua. Antes de pertenecer a la universidad, el edificio fue un hotel de lujo. Lo construyeron a principios de siglo, para extranjeros ilustres. Una de las innovaciones del hotel fueron sus salidas secretas para citas clandestinas, para pasajeros que huían de la prensa o viajeros que llegaban al país de incógnito. (De Santis, Filosofía 183)

En este contexto urbano y edilicio, Miró se incorpora a un micromundo con jerarquías y rivalidades asentadas. En principio se mantiene un tanto al margen, pues en su condición de mero empleado no tiene 
intenciones de involucrarse. Y su propio nombre, de hecho, puede ser sujeto a una interpretación geográfica de la ciudad: Miró es — si se viaja desde el centro— la siguiente calle paralela a Puán, y en este particular sentido Esteban Miró parece situarse más cerca de la nueva sede que de la antigua. ${ }^{27}$ Sin embargo, con el desarrollo de la historia, el personaje resulta asimilado por la trama de enemistades e, incluso, encuentra un relativo lugar de pertenencia en la facultad. Recordemos que, para escribir "su versión de los hechos", precisa volver a la ya derruida sede, imagen que abre y cierra la novela, y en ese movimiento podemos decir que, incluso, transfiere su protagonismo al edificio. ${ }^{28}$ Otro momento de relativa apropiación del edificio y la facultad se da cuando su puesto laboral está en riesgo a raíz de su enfrentamiento con Conde, director del instituto donde trabaja: "Por primera vez desde que trabajaba en la facultad pensé en el mundo amenazador defuera; no pasaría mucho tiempo antes de que tuviera que salir a buscar otro trabajo. Mi carrera como secretario del Instituto de Literatura Nacional estaba llegando a su fin” (De Santis, Filosofía 153; énfasis propio).

Pero el interior del edificio también se constituye como un peligro, más importante que el "afuera" de la ciudad, pues resulta una compleja amenaza de derrumbes - parciales a lo largo de toda la historia, y estructural en el final-, de enemistades con los profesores, de riesgosas expediciones al cuarto piso, de muerte e, incluso, de cierta otredad indefinida, una suerte de "naturaleza" propia del lugar: "Había crujidos en todas partes, pero eran los ruidos del edificio, que tenía una vida secreta. No eran sonidos humanos” (De Santis, Filosofía 64). Esta múltiple amenaza que encierra el edificio se deriva no de una personificación, sino más bien de cierta ecologización del espacio, que cuenta con una variada fauna: plagas de ratas, cucarachas, polillas, pulgas de papel, "insectos que comen la madera, los pisos, las vigas" (20), hurones y hasta una rana y una libélula. Lo animal marca las posibilidades de la presencia próxima pero desconocida; en una de sus aventuras al cuarto piso, Miró nos transmite: "La oscuridad se hizo completa y movediza. Tuve la sensación de que un animal enorme y viscoso reptaba bajo la montaña de papel” (67). Y la proliferación de especies animales se hace extensiva a la caracterización de los mismos profesores, cuando Conde le explica a Miró: "Esa loca [Granados] no es mi amiga. Solamente quiere arrancarme a Brocca de las manos. Siempre hay buitres que esperan que uno encuentre algo para lanzarse sobre la presa” (24).

A partir de la descripción precedente, tenemos que el edificio de la calle 25 de Mayo presenta un límite borroso y difícil de discernir entre lo natural y lo hecho por el hombre. En tal sentido, podemos proponer una lectura que asocie esta representación de la Facultad de Filosofía y Letras con el castillo prototípico del género gótico, según la descripción trazada por Punter y Byron (259-262). En la comparación entre ambos modelos - uno como representación de un edificio real, otro como prototipo de edificación de un género-, encontramos un factor común múltiple: muros derruidos, pasillos intrincados, espacios laberínticos, sitios expulsivos que guardan misterios, apariencias engañosas, límites no muy claros entre lo humano y lo nohumano, entre lo natural y lo sobrenatural, y confusión sintomática de tiempos - Punter y Byron se preguntan si el castillo gótico pertenece al pasado o al presente (261), y el mismo interrogante lo podemos posar sobre el edificio de la calle 25 de Mayo, especialmente si tenemos en cuenta sus vínculos con el pasado, como vimos más arriba-. Además, frente a estos atributos del castillo y según nuestra comparación del edificio de Filosofía y Letras como un lugar laberíntico y misterioso, Punter y Byron afirman que, paradójicamente, el castillo gótico también se trata de un sitio de domesticidad, en donde la vida cotidiana continúa su curso (261). En la misma dirección, podemos encontrar esta peculiaridad en el edificio de 25 de Mayo: más allá de los derrumbes y las muertes, Miró continúa con su vida y con su trabajo a lo largo de la historia, por lo que aún dentro de los episodios extraordinarios de Filosofía y Letras queda lugar para lo cotidiano.

En el mencionado entorno ecológico-académico, con plagas de animales y profesores animalizados, encontramos también que el papel - la celulosa - tiene un rol preponderante: suerte de "flora" del sitio y, a la vez, parte de su arquitectura: "Las paredes de papel” (De Santis, Filosofía 41), "los muros de papel" (66), "un gran bloque de papeles" (67). El carácter "natural" de su presencia es menos decorativo que constitutivo: junto al agua incesante de un caño roto conforma en el cuarto piso un "pantano de papel" (200-201), e incluso leemos descripciones que muestran su condición "geológica": "Pilas de carpetas como accidentes 
naturales" (57), "montañas de monografías" (57), "montaña de papel” (67). ${ }^{29}$ A lo largo de la novela se mencionan las densas capas de papel que cubren toda superficie disponible y ejercen peso sobre la estructura original del edificio, por lo que se trata de un "ecosistema” en constante peligro de catástrofe. ${ }^{30}$ Además, las numerosas cajas de papeles que proporciona Conde son la fuente para la redacción de "Sustituciones", ese único y múltiple texto de Homero Brocca que Miró reescribe. ${ }^{31}$

Si el papel tiene la potencia de ser un transmisor de conocimiento, en Filosofía y Letras esta posible función se acaba en eso: en una potencia que no se actualiza. El rol principal del papel en la novela - ocupar un lugar - exalta su propia materialidad, en detrimento de su posibilidad de ser un transmisor de saber. El papel se nos presenta como una materia que coloniza el espacio. Esto constituye un problema que es reconocido desde la propia institución académica ficticia, que emite un informe sobre la acumulación desmedida de papeles en el cuarto piso: "En el Boletín Interno de la Facultad de Filosofía y Letras había aparecido un artículo titulado 'Causas de la clausura del cuarto piso. El saber ocupa lugar'” (De Santis, Filosofía 19). La ocupación del espacio por parte del conocimiento supone una contradicción —o al menos un contraste - entre disciplinas del saber no ligadas de manera directa a la materialidad, como las Letras o la Filosofía, y un conjunto de productos y/ o residuos - papeles, en ambos casos - que ellas generan. En tal vínculo, la parte material es una condición de existencia de las disciplinas (hace falta papel para que haya libros), aunque, al mismo tiempo, se convierte en una carga negativa, en una aglomeración insensata de materia inútil. ${ }^{32}$

Las pilas de papeles, de hecho, constituyen la imagen originaria que suscitó la escritura de Filosofía y Letras. El propio De Santis dice en una entrevista:

Cuando empecé a estudiar la carrera de Letras en Filosofía y Letras conocí el edificio que la facultad tiene en la calle 25 de Mayo, en plena city porteña. Es un edificio muy antiguo y sombrío y en esa época estaba casi desierto. Entonces circulaban muchas leyendas sobre él. Cuando empecé a escribir esa novela tenía el recuerdo de algo que había visto allí cuando tenía 18 años: una sala llena de papeles que trepaban hasta el techo. Era una imagen muy fuerte por lo que tenía de laberíntico, pero más por el saber desperdiciado, por la posibilidad que hubiera algo interesante en aquella montaña de papeles que nadie iba a leer jamás. Era lo contrario a una biblioteca. En una biblioteca, los papeles se ordenan y conservan. Aquí, estaban allí en medio del caos, la humedad, el polvo. Estaban allí para ser destruidos por el tiempo y el caos. Bueno, a partir de esa imagen empecé a armar la trama. (Wieser 74)

El papel es la plaga más peligrosa, más que el resto de la fauna referida anteriormente. En la voz de Novario encontramos una caracterización de la amenaza, ligada, en este caso, a un recuerdo fugaz de la narrativa de Brocca: "Un hombre, en una habitación llena de papeles, descubre por fin que esos papeles están rodeándolo, que son malignos, que se escriben solos" (De Santis, Filosofía 58; énfasis del original). El propio Miró recibe una advertencia del sereno (cuando aún no sabemos que es Brocca): "Las columnas son muy frágiles y pueden derrumbarse. Imagine que una se desploma sobre usted. Imagine sus gritos, sin nadie para oírlo" (41). Y la amenaza, por momentos, se convierte en daño concreto: Miró queda atrapado "debajo de una montaña de papel" (69) y cuando escapa advierte que "tenía las piernas entumecidas, el tobillo derecho me dolía. En la boca tenía gusto a sangre" (69). Otro ejemplo de la amenaza concretada lo hallamos en la descripción de la muerte del estudiante Honorio, "aplastado por una tonelada de monografías" (59). De esta manera, la acumulación descontrolada de papel representa un constante peligro de muerte y derrumbes. Miró, en una de sus primeras visitas al cuarto piso, adivina el carácter planificado del (des)orden imperante:

Un silencio absoluto nacía en aquellos papeles muertos juntados año tras año y que superponían, a la deteriorada arquitectura, un dibujo de pasillos estrechos, puentes, columnas vacilantes, pasajes clausurados. Por primera vez me fue revelado que aquel orden no era casual, que habia un plan detrás del aparente caos de papeles; adiviné, más allá de los zigzagueantes muros formados por las carpetas, la profundidad de un orbe cerrado que nada tenía que compartir con los pisos inferiores. Desde alguna parte reinaba, invisible, el Arquitecto. (De Santis, Filosofía 40; énfasis propio) 
De manera progresiva, el protagonista advierte en la figura de Brocca una presencia fantasmal, suerte de demiurgo que escribe la trama y maneja los personajes a piacere. Por ejemplo, ante una propuesta de Novario, Miró sostiene:

El trabajo que me había encargado Conde había sido la primera invitación que un fantasmal Brocca me enviaba para que yo entrara en su región de sombras; aquí llegaba la segunda. Acepto, le dije a Novario, pero en realidad le respondía a Brocca. (De Santis, Filosofia 60-61)

Sin embargo, solo en el final de la novela el narrador confirma que el derrumbe edilicio es consecuencia de las maniobras de Brocca:

El edificio y la novela guardaban una complicada correspondencia que él era el encargado de vigilar. El mecanismo que armó no era determinista: Brocca provocaba el destino, pero su argumento no estaba cerrado del todo [...]. No le interesaba matar, sino escribir: el crimen era apenas un alimento para la tensión de la trama [...]. Mientras tanto, trabajaba para demoler el edificio, porque quería transformarlo en símbolo. En literatura, sostenía, para construir algo hay que destruirlo, y un escritor tiene que empezar a planear el final desde que escribe la primera línea. (De Santis, Filosofia 215-216)

De todos modos, como lo anuncia el fragmento citado, Brocca tampoco controla la totalidad del argumento. Más adelante, Miró nos informa: "En su novela yo huía con los papeles [de la novela de Brocca] bajo el brazo; apenas abandonaba el edificio, se producía el derrumbe. En la desprolija realidad, el derrumbe se me anticipó" (De Santis, Filosofía 220). Ante este desenlace, podemos recuperar, otra vez, el paralelismo con el castillo gótico, pues en ambos casos se trata de edificios que generan un efecto de desubjetivación: "Entre sus paredes uno puede verse 'sujeto' a una fuerza que es completamente resistente a los intentos del individio por imponer su propio orden” (Punter y Byron 262; traducción propia). ${ }^{33}$ Así, tenemos que el edificio escapa incluso a la propia voluntad del "Arquitecto" Brocca. En esa distancia respecto al planificador de las muertes - que, huelga decirlo, no planifica la suya propia-, anunciada al final de la novela, distinguimos el último argumento que constituye a la Facultad de Filosofía y Letras, a su sede de la calle 25 de Mayo, como el verdadero protagonista de la novela de De Santis.

\section{Bibliografía}

Borges, Jorge Luis. “El cuento policial”. Borges oral. Bruguera, 1980, pp. 69-88.

Borges, Jorge Luis. “El escritor argentino y la tradición”. Obras Completas 1923-1972. Emecé, 1974, pp. 267-274.

Bourdieu, Pierre. Homo academicus. Siglo XXI, 2008.

Bourdieu, Pierre. Las reglas del arte. Anagrama, 1995.

Canto, Estela. Borges a contraluz. Espasa Calpe, 1989.

Chesterton, Gilbert Keith. "La cruz azul”. El candor del Padre Brown. Losada, 1948.

Contreras, Sandra. Las vueltas de César Aira. Beatriz Viterbo Editora, 2008.

De Santis, Pablo. Filosofia y Letras. Seix Barral, 2002.

De Santis, Pablo. La traducción. Planeta, 1998.

De Santis, Pablo. Páginas mezcladas. Colihue, 2009.

De Rosso, Ezequiel. Nuevos secretos. Transformaciones del relato policial en América Latina. 1990-2000. Liber Editores, 2012.

Foucault, Michel. Histoire de la folie à l'áge classique. Gallimard, 1977.

Foucault, Michel. "La locura, la ausencia de obra". Entre filosofía y literatura. Obras esenciales. Vol. I, Paidós, 1999, pp. 269-278.

Foucault, Michel. “La locura y la sociedad”. Entre filosofía y literatura. Obras esenciales. Vol. I, Paidós, 1999, pp. 361-368.

Gamerro, Carlos. "Para una reformulación del género policial argentino". El nacimiento de la literatura argentina y otros ensayos. Norma, 2006, pp. 79-91. 
Ginzburg, Carlo. "Indicios. Raíces de un paradigma de inferencias indiciales". Mitos, emblemas, indicios. Morfología e historia. Prometeo Libros, 2013, pp. 171-221.

Holquist, Michael. "Whodunit and Other Questions: Metaphysical Detective Stories in Postwar Fiction". The Poetics of Murder. Detective Fiction and Literary Theory, editado por Glenn W. Most y William W. Stowe, Harcourt Brace Jovanovich Publishers, 1983, pp. 149-174.

Jacovkis, Natalia. "Latin American Crime Fiction". Critical Insigths. Crime and Detective Fiction, editado por Rebecca Martin, EBSCO Publishing, 2013.

Konstantinova, Iana. "Borgesian Texts, Murders, and Labyrinths in Filosofia y Letras by Pablo De Santis". Variaciones Borges, n. ${ }^{\circ} 29,2010$, pp. 161-176.

Konstantinova, Iana. "Detectives, Secret Societies, and Translators: The Mysteries of La traducción by Pablo De Santis". Monographic Review/Revista Monográfica, n. ${ }^{\circ}$ 22, 2006, pp. 196-206.

Kracauer, Siegfried. La novela policial: un tratado filosófico. Paidós, 2010.

Lafforgue, Jorge. "Prólogo". Cuentos Policiales Argentinos. Aguilar / Altea / Taurus / Alfaguara, 1997, pp. 9-22.

Lafforgue, Jorge. "Reintroducción: género, parodia, lecturas". Asesinos de papel. Ensayos sobre narrativa policial, compilado por Jorge Lafforgue y Jorge B. Rivera, Colihue, 1996, pp. 105-115.

Maltz, Hernán. Pablo De Santis y el género policial. Editorial de la Facultad de Filosofía y Letras de la Universidad de Buenos Aires, 2020.

Merivale, Patricia y Susan Elizabeth Sweeney. Detecting texts. The metaphysical detective story from Poe to postmodernism. University of Pennsylvania Press, 1999.

Néspolo, Jimena. "Escrituras parasitarias: el factor Borges en cuatro novísimos narradores argentinos (Jorge Consiglio, Marcelo Damiani, Pablo De Santis, Marcos Herrera)". Boletín de Reseñas Bibliográficas, n. 9/10, Instituto de Literatura Hispanoamericana, Facultad de Filosofía y Letras, Universidad de Buenos Aires / Fundación Konex, 2007, pp. 153-162.

Piglia, Ricardo. "La lectura de la ficción". Crítica y ficción. Anagrama, 2006, pp. 9-19.

Piglia, Ricardo. "Lectores imaginarios". El último lector. Anagrama, 2005, pp. 77-102.

Punter, David y Glennis Byron. “The Haunted Castle”. The Gothic. Blackwell Publishing, 2004, pp. 259-262.

Rivera, Jorge B. "Introducción al relato policial en la Argentina”. Asesinos de papel. Ensayos sobre narrativa policial, compilado por Jorge Lafforgue y Jorge B. Rivera. Colihue, 1996, pp. 83-104.

Rosenblum, Joseph. "Academic Mystery Fiction". Critical Survey of Mystery and Detective Fiction, editado por Carl Rollyson, vol. 5, Salem Press, 2008, pp. 2005-2010.

Saítta, Sylvia. "Ciudades revisitadas". Revista de Literaturas Modernas, n. ${ }^{\circ} 34,2004$, pp. 135-149.

Saítta, Sylvia. "Un thriller académico". Trespuntos, n. ${ }^{\circ}$ 105, 1999, p. 74.

Sasturain, Juan. "Hammett, el amigo americano". Ficciones policiales argentinas (1870-2015). Crimen y pesquisa. El género policial en la Argentina (1870-2015): literatura, cine, televisión, historieta y testimonio, compilado por Román Setton y Gerardo Pignatiello, Título, 2016, pp. 35-41.

Siegrist, Paul. "Latin American Mystery Fiction". Critical Survey of Mystery and Detective Fiction, editado por Carl Rollyson, vol. 5, Salem Press, 2008, pp. 1994-2001.

Wieser, Doris. "Pablo De Santis (Argentina). 'La inteligencia exagerada termina convertida en tontería'”. Crimenesy sus autores intelectuales. Entrevistas a escritores del género policial en América Latina y África lusófona, GOEDOC, Dokumenten-und Publikationsserver der Georg-August-Universität, 2012, pp. 66-82.

\section{Notas}

* Artículo de reflexión-investigación. Este artículo forma parte de mi tesis doctoral Pablo De Santis y el género policial, realizada entre 2015 y 2019 gracias a una beca doctoral interna del Conicet. 
[1] El relato policial académico —o, en uno de los nombres que recibe en inglés, the academic mystery fiction- tiene mayor arraigo, por supuesto, en países con tradiciones inveteradas de campus universitarios, como Inglaterra o Estados Unidos — para un panorama de dicho subgénero puede consultarse Rosenblum (2005-2010)—. Y, a diferencia de estos países, resulta curioso que en la Argentina exista un conjunto de novelas policiales académicas sin campus, pero con algunos representantes —como Filosofía y Letras, de De Santis, o La cátedra, de Casullo- que ponderan el rol del edificio universitario en las historias que narran.

[2] A esta lista podemos sumarle otras ficciones, no policiales, pero que también forman parte de un conjunto de historias académicas argentinas, en tanto seleccionan personajes y/o ámbitos universitarios: Los misterios de Rosario (1994) y El congreso de literatura (1997), de César Aira; Filo (2003), de Sergio Olguín; Pegamento (2004), de Gloria Pampillo; Las teorias salvajes (2008), de Pola Oloixarac; Cataratas (2015), de Hernán Vanoli, y Plato paceño (2015), de Alfredo Grieco y Bavio.

[3] La restricción dada por el componente universitario-académico deja fuera de nuestro corpus a una figura bastante habitual de la novela policial nacional: el periodista-investigador. Renzi es, por cierto, un caso del periodista-investigador, pero, al mismo tiempo, es un sujeto formado en la universidad. No ocurre lo mismo, por poner un ejemplo paradigmático, con el personaje Daniel Hernández, que lleva a cabo las investigaciones en varios cuentos de Rodolfo Walsh. Vale aclarar que esto no implica una valoración de "lo universitario" en detrimento de otros conocimientos, sino que se trata, sencillamente, de un criterio para delimitar un conjunto de ficciones.

[4] Saítta, en una sucinta pero provechosa reseña, consigna elementos de Filosofía y Letras situables en una línea borgeana: la novela de un autor que antes ha tenido otro autor; la reflexión sobre los vínculos entre ficción y realidad; el uso de una estructura narrativa en la que, como un juego de muñecas rusas, cada ficción siempre contiene otra ficción ("Un thriller" 74). Néspolo analiza la poética borgeana basada en las escrituras parásitas y cómo esta poética es empleada por cuatro escritores, entre ellos, Pablo De Santis; si bien Néspolo focaliza su análisis en El caligrafo de Voltaire, su lectura es muy productiva, pues resulta imposible evaluar Filosofía y Letras sin una consideración sobre la idea de los textos que viven de otros textos (153-162). Por último, Konstantinova efectúa un análisis que establece numerosos puntos de convergencia entre la novela de De Santis y el cuento "El jardín de senderos que se bifurcan”, de Borges (“Borgesian Texts” 161-176).

[5] Por supuesto, se puede rebatir que el "factor Borges" también está presente en la relación entre Piglia y De Santis si, por ejemplo, consideramos una genealogía de la literatura argentina que los tenga a ambos como herederos de Borges. Aquí, de todas formas, delimitamos una comparación puntual que resulta más pertinente en el vínculo De Santis-Piglia sin Borges o, mejor dicho, con Borges de fondo.

[6] De manera recíproca, Asesinos de papel, de Jorge Lafforgue y Jorge B. Rivera —otro texto publicado originalmente en 1977-, marca el punto de inflexión que constituye y legitima al género policial como objeto de estudio de la academia (De Rosso 79-80).

[7] Jorge B. Rivera, además, apunta que ese saber lingüistico de Renzi es un "avatar del saber lógico (y cabalístico) del detective Erik Lönnrot [del cuento 'La muerte y la brújula']” (101; énfasis del original). Si esta afirmación nos devuelve a la imposibilidad de escapar del "factor Borges", al menos nos permite notar que el detective Lönnrot es un intelectual letrado, pero no académico en sentido institucional, y esa es la clave con la que conectamos a Piglia y De Santis sin Borges o, como decíamos antes, con Borges de fondo.

[8] Hoy en día, la Facultad de Filosofía y Letras de la Universidad de Buenos Aires funciona principalmente en la calle Puán 480, aunque en la sede de la calle 25 de Mayo 217/221 funcionan varios institutos —además del Laboratorio de Idiomas de la Universidad de Buenos Aires-, entre ellos, el Instituto de Literatura Argentina "Ricardo Rojas", el Instituto de Literatura Hispanoamericana y el Instituto de Filología y Literaturas Hispánicas “Dr. Amado Alonso”. En la novela, el protagonista Esteban Miró trabaja en el ficticio Instituto de Literatura Nacional.

[9] El relato de Piglia también recrea elementos ambientales del género, pero estos están ligados a la tradición de la serie negra, como la presencia de personajes marginales, ajustes de cuentas y violencia física (Rivera 101).

[10] En una entrevista brindada a Juan Sasturain en el programa televisivo Disparos en la biblioteca (puntualmente en el segundo capítulo de la primera temporada, titulado "El extraño caso del señor Renzi”), Piglia dice que la solución de Renzi, en "La loca y el relato del crimen”, resulta "la única vez que la Facultad de Filosofía [y Letras] sirvió imaginariamente para resolver un crimen”.

[11] Rusnik no es el único loco usado por Conde. El cuento fictivo "Sustituciones", compuesto de incontables versiones, se nutre de reescrituras de más pacientes psiquiátricos. Dice Conde: "Mi hermano, que es médico psiquiatra, me ayudó mucho. Trabajó durante décadas en un centro de salud mental especializado en trastornos intelectuales. Muchos pacientes llegaban hasta él con papeles cosidos a la ropa o prendidos con alfileres a la camisa. Mi hermano hacía ciertos juegos terapéuticos que consistían en reescribir el cuento" (De Santis, Filosofía 37). 
[12] En la referencia bibliográfica marcamos dos páginas: la 11 y la 222. Consideramos relevante señalar ambas, la del comienzo y la del final, pues, en conjunto, enmarcan la narración de Miró, pero, además, enfatizan la idea de que su relato es, justamente, una entre muchas versiones posibles.

[13] La presencia de médicos, enfermedades, pacientes y fármacos es otra constante en la narrativa de De Santis (por ejemplo, en El teatro de la memoria o en el cuento "El paciente de Faraday").

[14] Apenas tomamos una idea de Foucault, pero también podríamos pensar que en Filosofía y Letras la locura funciona en al menos dos sentidos: los locos son esas "mentes brillantes" que poseen un acceso privilegiado a la verdad y, al mismo tiempo, la locura es una carga que debe ser señalizada y excluida (literalmente, a través de la Casa Spinoza). Ambos significados son analizados por Foucault, ya que cada uno predomina en distintos períodos históricos. Para aproximarse a esta cuestión resulta útil el breve texto "La locura y la sociedad" (361-368). Respecto a la evolución de la locura y cómo cambió su estatuto en distintos órdenes sociales, una referencia obligada son, por lo menos, los dos primeros capítulos de su Historia de la locura en la época clásica. Histoire 13-91).

[15] Si bien citamos a Piglia, no debemos pasar por alto que esta idea ya había sido expresada muchos años antes, a comienzos del siglo XX, por Gilbert Keith Chesterton. En "La cruz azul", primer relato en que figura el Padre Brown, el narrador nos introduce en los pensamientos de un famoso investigador francés: "Y Valentin se decía - con razón- que su cerebro de detective y el del criminal eran igualmente poderosos. Pero también se daba cuenta de su propia deventaja: 'El criminal — pensaba sonriendo-es el artista creador, mientras que el detective es solo el crítico"' (13).

[16] Nuestra sugerencia es una paráfrasis del subtítulo del primer libro escrito en conjunto por Karl Marx y Friedrich Engels: $L a$ sagrada familia, o Critica de la critica critica.

[17] Podríamos pensar en el cuento "El congreso", de Borges, como un antecedente en el que se registra de manera burlona el quehacer de los letrados.

[18] En general, los estudiosos - Saítta ("Un thriller" 74), Néspolo (153-162), Konstantinova ("Borgesian Texts" 161-176) y Wieser (66-82) - coinciden en observar una matriz policial que podemos hacer extensiva, en mayor o menor medida, a casi toda la narrativa de De Santis. Es curioso que el autor, por su parte, reniega de esta totalización clasificadora de su obra y afirma que solo escribió dos novelas policiales: Filosofía y Letras y El Enigma de París (Wieser 66-82); pero, dado que la entrevista citada fue publicada en 2012, también podríamos agregar a la perspectiva de De Santis su novela Crímenes y jardines, de 2013.

[19] Jorge Lafforgue señala esta característica como propia de una tradición policial argentina de larga data ("Reintroducción" 105-115). En el caso de la novela de De Santis, el empleo del humor responde, según vemos, a una doble función: parodia del género policial y mofa del mundillo académico.

[20] Recordemos que este informe surge de una exigencia de la institución universitaria. Al comienzo de Filosofía y Letras, Miró declara: "Me cuesta mucho escribir, y creo que no me hubiera enfrentado a mis infinitas vacilaciones a la hora de trabajar, si no me hubieran encargado las autoridades de la facultad mi versión de los hechos, con la promesa de su publicación en el Boletín de Humanidades. Le destinarán, me dijeron, un número entero" (De Santis, Filosofia 10-11). La obligatoriedad se impone como una marca del relato que nos llega. En general, el registro de los acontecimientos en la forma de informes burocráticos es algo que en la literatura policial figura como una carga, como un peso insoportable: quizá el cenit de esto lo podamos encontrar en una novela fundacional de la tradición negra, Cosecha roja, de Dashiell Hammett, en la que el protagonista revoluciona una ciudad entera y provoca una serie incontable de muertes, pero se muestra reticente e incapaz de escribir el informe que le solicita la agencia para la que trabaja.

[21] La figura del traductor de policiales también está presente en La traducción. Allí tenemos al uruguayo Vázquez, que "había traducido novelas policiales para las colecciones Rastros y Cobalto" (De Santis, La traducción 33).

[22] "No hay ayudantes ni alumnos. Soy solamente yo, que voy de un lado a otro, y discurro y trato de conectar los indicios" (De Santis, Filosofía 88).

[23] En el original leemos: "A metaphysical detective story is a text that parodies or subverts traditional detective-story conventions - such as narrative closure and the detective's role as surrogate reader - with the intention, or at least the effect, of asking questions about mysteries of being and knowing which transcend the mere machinations of the mystery plot. Metaphysical detective stories often emphasize this transcendence, moreover by becoming self-reflexive (that is, by representing allegorically the text's own process of composition)" (Merivale y Sweeney 2). Por otra parte, huelga recordar que el concepto de policial metafísico ya había sido introducido por Holquist, quien plantea que el foco de estos relatos no gravita en torno a la investigación de la muerte, sino a la reflexión sobre la vida (173). 
[24] Doris Wieser (75) compara la construcción fantasmagórica del viejo edificio de la facultad con la quinta Triste-le-Roy de "La muerte y la brújula", aunque, agregamos nosotros, en el cuento de Borges no hay, al menos explícitamente, una apelación a un referente edilicio del mundo real, si se nos permite la expresión. De cualquier modo, debemos recordar que, según Canto, la quinta Triste-le-Roy estaría inspirada en el hotel Las Delicias, en Adrogué (19). El propio Borges declara, por cierto, que su inspiración provino de las quintas de Adrogué ("El escritor" 270).

[25] La televisión funciona en la novela como un sugestivo contrapunto frente al mundillo académico de las letras: recordemos que, en su casa — sitio al que le otorga el significado de su libertad—, Miró ve televisión.

[26] La descripción coincide con elementos históricos reales, pues originalmente el edificio fue un lujoso hotel construido por el empresario Nicolás Mihanovich a principios del siglo XX.

[27] Ya hemos mencionado en una nota al pie precedente que la Facultad de Filosofía y Letras funciona sustantivamente en la calle Puán 480. Por otra parte, aún hay otro sentido posible, más evidente, que podemos hallar en el nombre del protagonista, relacionado con su condición de testigo ocular: su apellido es el verbo mirar conjugado en la tercera persona del singular del pretérito perfecto simple del modo indicativo.

[28] Miró confiesa al principio del relato: “Descubrí que solo aquí podía comenzar a escribir la verdad” (11). El lugar de la ficción, el edificio que ella narra, se transforma en condición necesaria para la historia referida. En este punto, podemos discernir un leitmotiv en las obras de De Santis: el derruido edificio que habita el protagonista en Desde el ojo del pez, la casa de Ediciones "El fuselaje” en Páginas mezcladas, el Hotel del Faro y el propio faro en La traducción, la torre Eiffel aún inconclusa en El enigma de París (y la idea de que la torre Eiffel puede caerse, en Páginas mezcladas ), el hospital militar de la Patagonia en el cuento "El paciente de Faraday" o la casa de Craig (que también funciona como academia de detectives) en Crímenes y jardines. Sin tales edificios, sería difícil por no decir imposible- concebir las historias que cada una de dichas ficciones cuenta. El cenit de esta idea lo hallamos en $L a$ sexta lámpara, novela centrada en un edificio que nunca se llega a construir, Zigurat, que solo existe en los planos y las figuraciones del arquitecto Balestri.

[29] Este aspecto "natural" nos permite ceñir aún más la comparación del edificio de Filosofía y Letras con el castillo del género gótico, en lo relativo a los límites no muy claros entre lo humano y lo no-humano, entre lo natural y lo sobrenatural.

[30] La imagen de papeles que cubren todo el espacio ya aparece en Páginas mezcladas, otra novela de De Santis, publicada escaso tiempo antes de Filosofia y Letras: "EL SUELO ESTABA OCUPADO CASI TOTALMENTE POR LIBROS DE TODAS LAS ÉPOCAS, MANCHADOS, ROTOS, SIN TAPAS, ENVUELTOS EN TELARAÑAS. EN ALGUNOS RINCONES LA HUMEDAD HABÍA CONVERTIDO A LOS LIBROS EN UN BLOQUE ÚNICO DE CIENTOS DE MILES DE PÁGINAS. [Montaner] AVANZÓ PRIMERO ENTRE LOS LIBROS, QUE SE LEVANTABAN EN COLUMNAS, Y LUEGO SOBRE ELLOS” (De Santis, Páginas 55; mayúsculas del original). La preocupación por los papeles y los libros en tanto objetos, en tanto materia que ocupa espacio, es un aspecto que se repite en la narrativa de De Santis, y que también podemos conectar con aquella similar preocupación expuesta en el cuento "La biblioteca de Babel", de Borges.

[31] Más allá de su propia materialidad en tanto "cientos y cientos de páginas desordenadas", la versión de Miró de "Sustituciones" aporta núcleos interpretativos que son aplicables a toda la novela de De Santis: el descreimiento sobre "los hechos" que conforman "la historia"; las dudas sobre la existencia de un "texto original"; la circulación de versiones y versiones que se transforman y se reemplazan sin fin; la ficción como un experimento que juega con la vida y la muerte.

[32] Esta potencial pérdida de valor simbólico y reducción del papel a su mera materialidad es analizada por Bourdieu. En su estudio sobre el mercado editorial francés de mediados-fines del siglo XX, reconoce la posibilidad de que el valor simbólico que reviste el papel bajo la forma de un libro sea finalmente anulado y que el único valor resultante esté dado por el peso del papel. Esto sucede con mayor probabilidad en el caso de una empresa de ciclo de producción largo "basado en la aceptación del riesgo inherente a las inversiones culturales y sobre todo en el acatamiento de las leyes específicas del comercio del arte: al carecer de mercado en el presente, esta producción volcada por entero hacia el futuro tiende a construir stocks de productos siempre amenazados por el peligro de la regresión al estado de objetos materiales (valorados como tales, es decir por ejemplo al peso del papel)" (Las reglas 215; énfasis propio). Una idea similar deseamos transmitir sobre los papeles de Filosofía y Letras: una vez que ya no son más valorados por el saber que transmiten bajo la forma de monografías, su existencia se reduce a esa "regresión al estado de objetos materiales" que apunta Bourdieu.

[33] En el original leemos: "Within its walls one may be 'subjected' to a force that is utterly resistant to the individual's attempt to impose his or her own order" (Punter y Byron 262). 
Licencia Creative Commons CC BY 4.0

Cómo citar este artículo: Maltz, Hernán. "El papel de la academia. Sobre Filosofía y Letras (1998) de Pablo De Santis". Cuadernos de Literatura, vol. 24, 2020. https://doi.org/10.11144/Javeriana.cl24.pafl 